\title{
Long-term outcomes after lung-sparing surgery for epithelial mesothelioma
}

\author{
Cristiano Breda ${ }^{1}$, Simone Furia ${ }^{1}$, Giuseppe Lucchini $^{2}$, Antonio Zaccaria ${ }^{1}$, Enrico Verderi ${ }^{1}$, \\ Giuseppe Natale ${ }^{1}$, Fabio Lo Giudice ${ }^{1}$, Roberta Cavallin ${ }^{1}$, Andrea Ferronato ${ }^{1}$, Paolo Fontana ${ }^{1}$ \\ ${ }^{1}$ Thoracic Surgery Unit, Ospedale dell'Angelo, Venezia Mestre, Italy; ${ }^{2}$ Department Healthcare Medical Management, Biostatistic Service, ASST \\ Mantova, Mantova, Italy \\ Contributions: (I) Conception and design: C Breda, S Furia, P Fontana; (II) Administrative support: S Furia, E Verderi, R Cavallin; (III) Provision of \\ study materials or patients: C Breda, A Zaccaria, P Fontana; (IV) Collection and assembly of data: All authors; (V) Data analysis and interpretation: C \\ Breda, S Furia, G Lucchini; (VI) Manuscript writing: All authors; (VII) Final approval of manuscripts: All authors. \\ Correspondence to: Simone Furia, MD, PhD. Thoracic Surgery Unit, Ospedale dell'Angelo, via Paccagnella 11, 30174 Venezia Mestre, Italy. \\ Email: simone.furia@aulss3.veneto.it.
}

Background: This observational study evaluates retrospectively the long-term outcomes after pleurectomy/decortication for pleural mesothelioma, with and without the resection/reconstruction of diaphragm and pericardium.

Methods: Data from 155 consecutive patients undergoing lung-sparing surgery for epithelial pleural mesothelioma were reviewed. Selection criteria for surgery were cT1-3, cN0-1, good performance status, age $<80$ years. Perioperative Pemetrexed-Platinum regimen was administered as induction in 101 cases $(65.2 \%)$ and as adjuvant treatment in 54 cases $(34.8 \%)$. Extended pleurectomy/decortication was performed in 87 cases $(56.12 \%)$. In 68 patients $(43.87 \%)$ standard pleurectomy/decortication was performed without resection/reconstruction of diaphragm and pericardium, when tumour infiltration was deemed absent after intraoperative frozen section. The log-rank test and Cox regression model were used to assess the factors affecting overall survival and recurrence free survival.

Results: Median follow-up was 20 months. The 2- and 5-year survival rate was $60.9 \%$ and $29.2 \%$ with a median survival of 34 months. An improved survival was observed when standard pleurectomy/decortication was carried out $(\mathrm{P}=0.007)$. A significant impact on survival was found comparing the TNM-stages $(\mathrm{P}=0.001)$, pT $(\mathrm{P}=0.002)$ and $\mathrm{pN}$ variables $(\mathrm{P}=0.001)$. Multivariate analysis identified the $\mathrm{pN}$-status $(\mathrm{P}=0.003)$ and standard pleurectomy/decortication $(\mathrm{P}=0.017)$ as predictive for longer survival. The recurrence-free survival $>12$ months was strongly related to the overall survival $(\mathrm{P}<0.001)$. The macroscopic complete resection $(\mathrm{P}=0.001)$, TNM-stage $(\mathrm{P}=0.003)$ and $\mathrm{pT}$-status $(\mathrm{P}=0.001)$ are related to relapse.

Conclusions: Within multimodal management of pleural mesothelioma, lung-sparing surgery is a valid option even with more conservative technique. A benefit for a longer survival was observed in the early stage of disease, with pN0 and when pleurectomy/decortication is carried out, preserving diaphragm and pericardium. Recurrence is not affected by the type of surgery, and a recurrence-free interval $>12$ months is predictive of an increased survival when the macroscopic complete resection is achieved.

Keywords: Pleural mesothelioma; epithelial mesothelioma; pleurectomy/decortication; lung-sparing surgery

Submitted May 13, 2021. Accepted for publication Aug 13, 2021.

doi: $10.21037 /$ jtd-21-691

View this article at: https://dx.doi.org/10.21037/jtd-21-691

^ ORCID: 0000-0002-6195-2254.

(c) Journal of Thoracic Disease. All rights reserved. 


\section{Introduction}

Malignant pleural mesothelioma (MPM) is a rare tumor with a poor prognosis, and presents a median survival from diagnosis of less than 7 months for untreated patients undergoing palliative care (1). With cytoreductive purpose, the current protocols are based on a multimodal management, involving perioperative chemotherapy, surgery and radiotherapy (2-5), which, if combined, improve postoperative outcomes and overall survival $(6,7)$. The role of surgery as a forefront approach has been always debated, but a recent analysis reported an improved overall survival (32 vs. 10 months $\mathrm{P}<0.0001$ ), comparing trimodality treatment including the lung-sparing surgery versus chemotherapy alone, based on a combination of platin and pemetrexed. (8). Since it is not possible to obtain a radical tumour clearance, the goal of surgery is to achieve the macroscopic complete resection (MCR) by reducing the tumour burden (9-11). Even though the optimal surgical strategy is still controversial, the lung-sparing procedures have been recognized as associated with lower postoperative morbidity and mortality (12-14). These benefits are related to the preservation of normal anatomy which improves the survival and allows patients to better cope with further treatments in case of relapse. Two lung-sparing procedures are defined: the pleurectomy/decortication $(\mathrm{P} /$ $\mathrm{D})$ is described as the complete removal of the parietal and visceral pleural sheets and could be extended (EP/D) when the resection/reconstruction of diaphragm and pericardium is required. The EP/D has been the most recommended alternative to more invasive procedures and many surgeons are oriented towards the systematic resection of diaphragm and pericardium. The purpose of this report is to assess whether a conservative approach, through $\mathrm{P} / \mathrm{D}$, may affect the long-term outcomes such as overall survival (OS) and recurrence-free survival (RFS).

We present the following article in accordance with the STROBE reporting checklist (available at https://dx.doi. org/10.21037/jtd-21-691).

\section{Methods}

The study was conducted in accordance with the The Declaration of Helsinki (as revised in 2013). The study was approved institutional ethics committee of AULSS3 Serenissima of Venice-Italy (Prot. 0003576 of 11/01/2021) and individual consent for this retrospective analysis was waived. From 2009 to 2019 in the Thoracic Surgery Unit of the hospital of Venice Mestre, 207 consecutive lungsparing procedures for MPM were performed. For all patients, the diagnosis was histologically proven after videothoracoscopic pleural biopsies and pleurodesis. Among these patients, 28 with biphasic histotype diagnosed after surgery, were excluded from the present analysis and 24 patients were lost in the follow-up. Data from 155 patients were retrospectively reviewed. The mean age was 64.3 years with a median of 66 years. The baseline characteristics (Table 1) confirmed occupational or environmental exposure to asbestos $(85.2 \%)$ and predominance of the male gender (77.4\%). Preoperative work-up included thoracic and abdominal CT scan with contrast and FDG-PET scan. In a few cases, infiltration of the thoracic wall and the diaphragm was evaluated by MRI. Operability criteria were determined by performance status, cardiopulmonary function, and clinical staging. The multimodal treatment was applied through induction chemotherapy in 101 patients $(65.2 \%)$ and by adjuvant chemotherapy in 54 patients (34.8\%). The recommendations proposed by the Third Italian Consensus Conference for MPM have been adopted (15) in our center since 2015. In all cases, chemotherapy was based on 3 to 6 cycles of pemetrexed + platinum-derived drugs regimens. After induction chemotherapy, the response to treatment was always evaluated by a FDG-PET scan, in accordance with the modified RECIST guidelines (16). The surgical patients were selected by performance status (ECOG 0-1), by age ( $<80$ years) and by clinical TNM factors, following the eighth edition of TNM staging, according to the following FDG-PET results: from cT1 to cT3, no nodes or ipsilateral nodes and absence of distant metastases.

\section{Surgical techniques}

All of 155 patients underwent lung-sparing surgery. The surgical access was performed through a vertical thoracotomy, including the incision of the previous videothoracoscopy. Pleural thickening after the talc pleurodesis allowed the extrapleural dissection from the apex to the costophrenic angles. Through a blunt dissection on the extrapleural plane, the endothoracic fascia is separated from the parietal pleura. When mediastinal surface is explored, the phrenic nerve is entirely isolated and secured. The decision to carry out a pleurectomy or an extended pleurectomy is taken when the pericardium and the diaphragm are approached. The pleural layer is cleaved to be easily peeled off from the underlying structures. If infiltration was present and the detachment 
Table 1 Baseline characteristics of the population

\begin{tabular}{|c|c|c|c|}
\hline Characteristic & Total & $P / D(n=68)$ & $\mathrm{EP} / \mathrm{D}(\mathrm{n}=87)$ \\
\hline Mean age (years) & 64.3 & 64.34 & 64.22 \\
\hline Median age (years) & 66.0 & 66 & 67 \\
\hline \multicolumn{4}{|l|}{ Gender } \\
\hline Male & $120(77.4)$ & 57 & 63 \\
\hline Female & $35(22.6)$ & 11 & 24 \\
\hline \multicolumn{4}{|l|}{ Asbestos exposure } \\
\hline Total & $132(85.2)$ & 54 & 78 \\
\hline Professional & $94(60.6)$ & 35 & 59 \\
\hline Environmental & 33 (21.3) & 10 & 23 \\
\hline Household & $5(3.2)$ & 1 & 4 \\
\hline Uncertain & $23(14.8)$ & 14 & 9 \\
\hline \multicolumn{4}{|l|}{ Side } \\
\hline Right & $92(59.4)$ & 38 & 54 \\
\hline Left & $63(40.6)$ & 30 & 33 \\
\hline \multicolumn{4}{|l|}{ Clinical staging TNM } \\
\hline$I A+I B$ & $129(83.2)$ & 56 & 73 \\
\hline$I I+I I I A$ & $26(16.8)$ & 12 & 14 \\
\hline
\end{tabular}

$\mathrm{P} / \mathrm{D}$, pleurectomy/decortication; EP/D, extended pleurectomy/ decortication.

was hindered, a full thickness resection was performed. When the infiltration was doubtful and the diaphragmatic and/or pericardial involvement was focal, a frozen section was required. Depending on the surgeon choice, the amount of tissue to remove was related to the frozen sample results and in case of partial resection, the direct closure was the preferred option. Pericardial effusion was investigated with specimen for cytology. On the diaphragm, the total detachment of the pleura, saving as much muscle as possible, was always attempted. When a full-thickness involvement of the diaphragm imposed the resection and the prosthetic reconstruction, specimen from peritoneum was harvested for frozen section analysis. The decortication of the visceral pleura was performed with completely deflated lung. The detachment from parenchyma is carried out through a blunt dissection with cotton balls or fingers, following all reflections of the pleura, notably in the fissure and around pulmonary vessels at hilum. Depending on surgeon's choice, Argon beam coagulation was applied on small residues of normal pleura and to control the bleeding.
Lymphadenectomy was always accomplished, exploring the hilar and mediastinal stations. The lymph nodes from paravertebral, internal mammary, diaphragmatic chains were accurately harvested, when present. A postoperative intensive care admission was scheduled for all patients. According to the IASLC/IMIG recommendations (17), EP/ $\mathrm{D}$ was defined for procedures involving large resections requiring a prosthetic reconstruction of pericardium or diaphragm or both. $\mathrm{P} / \mathrm{D}$, defined by the preservation of pericardium and diaphragm, included the cases in which a direct suture was needed for accidental tears or small tears without infiltration at frozen section. For all procedures the goal was to achieve the MCR. Whenever the complete tumor removal was not possible, due to the intraoperative finding of mediastinal and/or chest wall infiltration, subtotal pleurectomy was labelled as R2 and staged IIIB. All histopathologic reports were reviewed according to the eighth edition of TNM staging system (18-20).

\section{Data collection and statistical analysis}

Data were retrospectively collected from the clinical records. Following data were reviewed for the statistical analysis: gender, type of surgery, TNM descriptors, pathological staging, recurrence and survival. Starting from the date of surgery, the long-term outcomes and the prognostic factors were evaluated in terms of OS and RFS. Descriptive statistics were used for exploratory data analysis. The difference in OS and RFS curves were estimated with the Kaplan-Meier method. Median survival times with $95 \%$ confidence intervals (CIs) and a log-rank test were conducted to determine the variation in the survival distribution for the different variables. Cox proportional hazard regression models were adopted to establish hazard ratios. Tests of Model Coefficients were run to evaluate the adequacy of variables to explain the events. Both OS and RFS multivariate analysis were performed with adjustment for Type of surgery, R2 surgery, pN. All P values were based on a 2 -sided hypothesis, and those $<0.05$ were considered statistically significant. Statistical analysis was performed with IBM SPSS Statistics, Version 25.0. Armonk, NY: IBM Corp.

\section{Results}

A total of $68 \mathrm{P} / \mathrm{D}$ (43.87\%) and $87 \mathrm{EP} / \mathrm{D}$ (56.12\%) were performed. Air leaks $>7$ days were the most frequent postoperative complication (54.8\%) and hemotransfusion 
Table 2 Major complications after surgery

\begin{tabular}{lccc}
\hline Complications & P/D, n (\%) & EP/D, n (\%) & Total, n (\%) \\
\hline Air leaks & $36(23.2)$ & $49(31.6)$ & $85(54.83)$ \\
Blood loss & $31(20.00)$ & $19(12.26)$ & $50(32.25)$ \\
$\quad \begin{array}{l}\text { Hemothorax requiring } \\
\text { surgery }\end{array}$ & $4(2.58)$ & $4(2.58)$ & $8(5.16)$ \\
Cardiovascular events & $6(3.87)$ & $5(3.22)$ & $11(7.09)$ \\
Other complications & $4(2.58)$ & $1(0.64)$ & $5(3.22)$ \\
\hline
\end{tabular}

$\mathrm{P} / \mathrm{D}$, pleurectomy/decortication; EP/D, extended pleurectomy/ decortication.
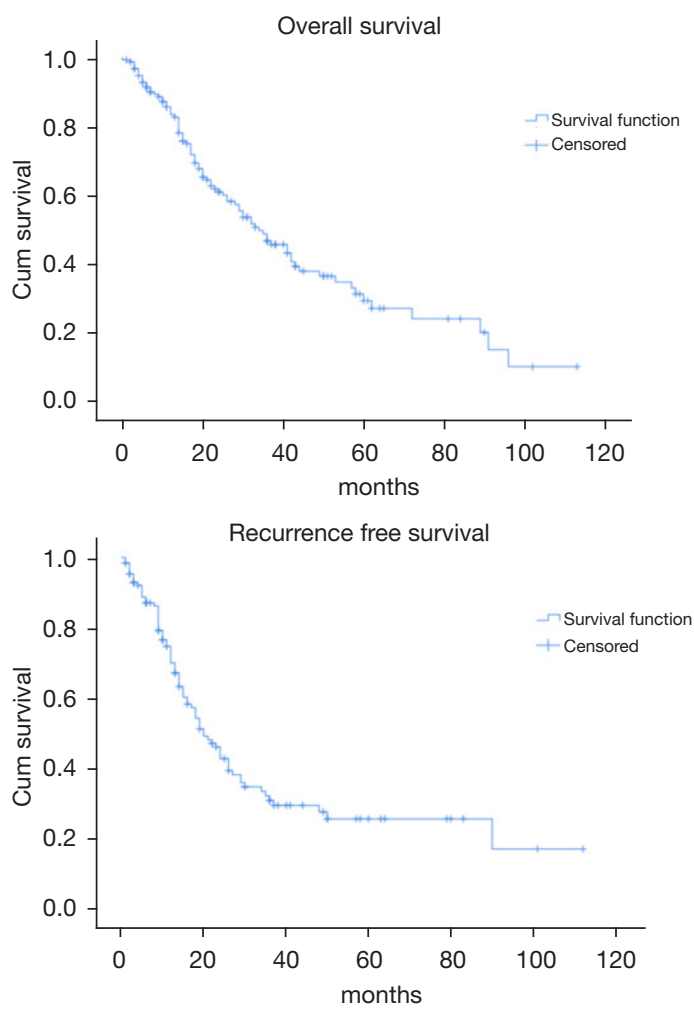

Figure 1 Outcomes. Long-term outcomes: overall survival (OS) and recurrence-free survival (RFS).

for $\mathrm{Hb}<9 \mathrm{~g} / \mathrm{dL}$ was needed for 50 patients $(32.3 \%)$. Cardiovascular events, including cardiac arrhythmia, ischemic attack and pulmonary embolism, occurred in 11 patients $(7.1 \%)$. Other complications as chylothorax, bowel obstruction and perforation were recorded for 5 patients (3.2\%). Sepsis and hemothorax requiring surgery, occurred in 8 cases $(5.2 \%)$. Complication rate was similar in the two groups of surgery. In one patient a cardiac tamponade related to a direct suture on the pericardium, was recorded after P/D (Table 2). Thirty- and ninety-day postoperative mortality was $0.64 \%$ and $3.2 \%$ respectively. All patients were followed up by a CT scan every 4-6 months and, in case of suspected recurrence, by FDG-PET scan. Adjuvant therapy was administered to those who did not receive induction treatment. In case of recurrence, a second-line chemotherapy was discussed in the multidisciplinary team and, for limited or localized relapse, intensity-modulated radiotherapy or redo-surgery were considered. Pathological staging was as follows: stage IA: 32 (20.6\%), IB: 67 (43.2\%), II: 12 (7.7\%), IIIA: 23 (14.8\%), IIIB: 21 (13.5\%). The different stages were equally represented for each type of surgery and the patients distribution was balanced in the two groups (chi-square test $\mathrm{P}=0.189$ ). The IIIB stage included locally advanced and technically unresectable tumors in which the MCR was not obtained. The R2 cytoreduction was performed as a combined result of the following intraoperative findings: multifocal infiltration of the chest $(n=5)$; adhesion/infiltration of mediastinal structures such as aorta, esophagus, superior cava vein, spine $(n=13)$; invasion of the peritoneum $(n=3)$, invasion of the thoracic inlet $(n=2)$; transmural infiltration of the pericardium with positive cytology in pericardial effusion $(\mathrm{n}=7)$. Patients R2 with incomplete tumour resection were $8(11.76 \%)$ in P/D and 13 in EP/D (14.94\%), showing an equal distribution between groups $(\mathrm{P}=0.64$ by chi-square test).

\section{Overall survival}

The OS time was calculated starting from the date of surgery. The median follow-up time after surgery was 20 (mean 27.8; range 1-113) months. The median time of survival was 34 months (SE 4.48, 95\% CI: 25.2-42.8), the 2 -year and the 5 -year survival rate were $60.9 \%$ and $29.2 \%$ respectively (Figure 1). At the univariate analysis (Table 3), a correlation between OS and gender or side of surgery was not found. In a comparison of the different surgical techniques, OS was found to be improved $(\mathrm{P}=0.007)$ when diaphragmatic and pericardial resections were avoided (Figure 2). The median survival time was 49 months for P/D (SE 7.98; 95\% CI: 33.34-64.66) and 22 months for EP/D (SE 2.86; 95\% CI: 16.38-27.61). The 2-year and 5 -year survival rate for $\mathrm{P} / \mathrm{D}$ were $75.5 \%$ and $41.6 \%$, for EP/D were $48.3 \%$ and $19.8 \%$ respectively. The 2 -year OS rate for the different TNM stages was as follows: IA $84.6 \%$, IB $63.3 \%$, II $58.3 \%$, IIIA $33.9 \%$, IIIB $48.3 \%$, with 
Table 3 Univariate analysis for OS and RFS

\begin{tabular}{|c|c|c|c|c|c|c|}
\hline Factors & \multicolumn{3}{|c|}{ os } & \multicolumn{3}{|c|}{ RFS } \\
\hline P/D & 7.988 & $33.34-64.66$ & 0.007 & 3.203 & $19.72-32.28$ & 0.118 \\
\hline EP/D & 2.864 & $16.38-27.61$ & & 2.856 & $9.40-20.60$ & \\
\hline Stage & & & 0.001 & & & 0.003 \\
\hline Stage IB & 4.155 & $27.86-44.14$ & & 3.481 & $17.18-30.82$ & \\
\hline Stage II & 5.265 & $3.00-42.00$ & & 1.309 & 19.34-24.56 & \\
\hline Stage IIIA & 3.367 & $7.40-20.60$ & & 6.642 & $9.98-36.02$ & \\
\hline Stage IIIB & 4.364 & $8.45-25.55$ & & 1.247 & $9.56-14.44$ & \\
\hline pT & & & 0.002 & & & 0.001 \\
\hline $\mathrm{pT} 1$ & 26.491 & $39.08-142.92$ & & 8.817 & $8.719-43.28$ & \\
\hline pT2 & 10.205 & 21.99-62.00 & & 2.857 & $18.40-29.60$ & \\
\hline pT3 & 4.431 & $14.31-31.68$ & & 4.891 & $8.41-27.59$ & \\
\hline pT4 & 4.364 & $8.45-25.55$ & & 1.247 & $9.56-14.44$ & \\
\hline RFS & & & $<0.001$ & & & \\
\hline RFS $\leq 12$ months & 0.369 & $8.276-9.72$ & & & & \\
\hline
\end{tabular}

OS, overall survival; RFS, recurrence free survival; P/D, pleurectomy/decortication; EP/D, extended pleurectomy/decortication.

a significant difference for $\mathrm{P}$ value $(\mathrm{P}=0.001)$. Accordingly with these findings, the analysis of the single descriptors of TNM staging (Figures 3-5) indicated a significant correlation for $\mathrm{pT}(\mathrm{P}=0.002)$ and $\mathrm{pN}(\mathrm{P}=0.001)$. Negative lymph-nodes increased the OS: 2-year and 5-year survival rates were $68.9 \%$ and $39.5 \%$ for N0 vs. $40.5 \%$ and $16.6 \%$ for N1. In the multivariate analysis (Table 4), the pN status and the P/D resulted as prognostic factors associated with survival.

\section{Recurrence free survival}

The recurrence free survival time was calculated from the date of surgery. The available data limited the analysis of the RFS to 129 patients (83.2\%). The median time of RFS was 20 months (SE 2.34; 95\% CI: 15.41-24.60); the 2-year and the 5 -year RFS rates were $46 \%$ and $25.7 \%$ respectively (Figure 1). With univariate analysis (Table 3), the influence of the different TNM stages of disease on RFS is statistically significant $(\mathrm{P}=0.003)$, however the $\mathrm{pN}$-status $(\mathrm{P}=0.57)$ and the $\mathrm{p} T$-status $(\mathrm{P}=0.001)$ presented a different impact, suggesting that patients at early $\mathrm{T}$-stage might have a lower risk of recurrences (Figures 3-5). In accordance with these observations, median RFS is better in case of P/D: 26 months (SE 3.20; 95\% CI: 19.72-32.28) rather than after EP/D: 15 months (SE 2.86; 95\% CI: 9.40-20.60); however a statistical difference $(\mathrm{P}=0.1)$ between the surgical techniques was not found (Figure 2). As expected, the R2 surgery deeply affected RFS and appeared to be an independent prognostic factor related to the risk of recurrence in the multivariate analysis (Table 4). As observed by some authors, the RFS interval is strongly related to OS (21). The 74 patients $(57.36 \%)$ who experienced their first relapse at more than 12 months after surgery, showed a strongly significant benefit $(\mathrm{P}<0.001)$ with a longer median survival time (30 vs. 9 months). 

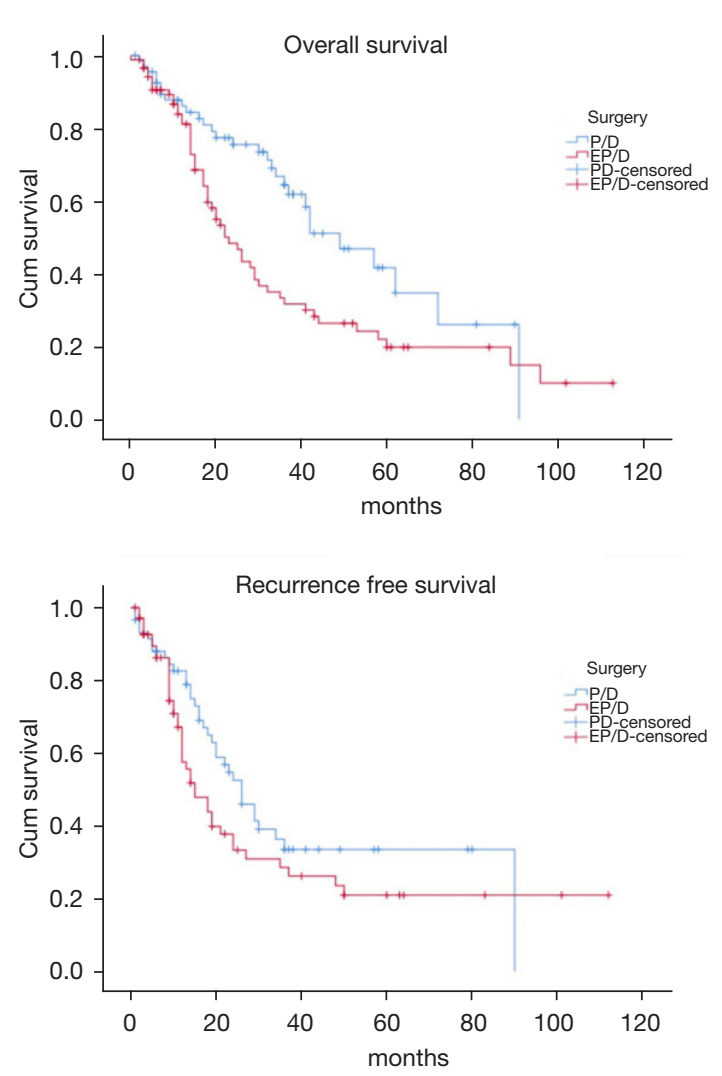

Figure 2 Surgery. Impact of the two type of surgery P/D vs. EP/ $\mathrm{D}$ for the long-term outcomes: $\mathrm{OS}(\mathrm{P}=0.007)$ and RFS $(\mathrm{P}=0.118)$. $\mathrm{P} / \mathrm{D}$, pleurectomy/decortication; EP/D, extended pleurectomy/ decortication; OS, overall survival; RFS, recurrence-free survival.

\section{Discussion}

In the past decades the lung-sparing surgery was considered for palliative purposes in MPM patients and it was reserved for those that could not be scheduled for extrapleural pneumonectomy (EPP), which remained the first-line surgical option. In recent years, agreeing not possible to obtain a radical resection R0 (13), the goal has become to achieve the MCR, attaining at most an R1 resection (22). It has been suggested that through the lung-sparing techniques this goal can be accomplished, and these procedures are recommended as the first choice for the maximal cytoreduction, due to better postoperative and long-term outcomes, reported by many authors (23-25). In two reviews it was showed that EP/D presents significantly lower perioperative morbidity and mortality when compared to EPP (2-3\% vs. 5-7\%), $(24,25)$ and a Metaanalysis (26) found that the EPP is related to 2,5-fold higher
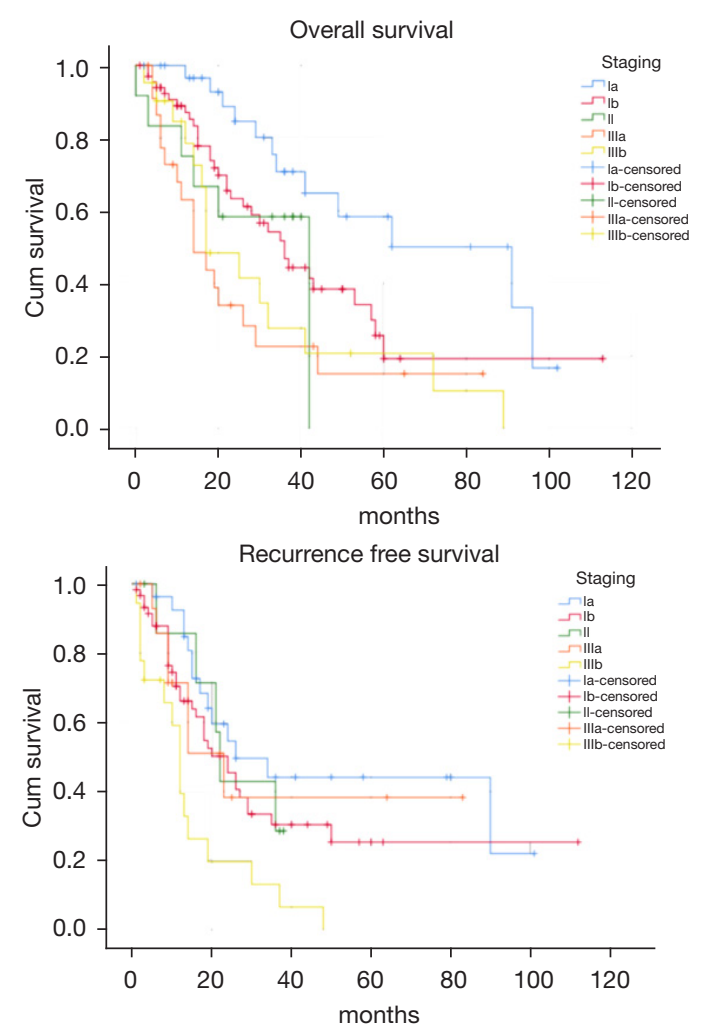

Figure 3 Staging. Distribution of the pathological TNM-staging groups for OS $(\mathrm{P}=0.001)$ and for RFS $(\mathrm{P}=0.003)$. OS, overall survival; RFS, recurrence-free survival.

perioperative mortality. Also in our series, the recorded perioperative mortality rate is consistent with these data as indicated by the Society of Thoracic Surgeons Database for higher-volume centers performing more than 5 procedures per year (27). According with these assumptions, a research based on the data derived from the National Cancer Database showed that the lung-sparing techniques have become the principal surgical procedure carried out on MPM patients in the United States $(28,29)$. This shift towards a less invasive surgery is based on the conservation of normal anatomy which is potentially proportional to favorable postoperative long-term outcomes. The 2-year survival reported for lung-sparing surgery versus EPP, revealed comparable results without statistical difference (47\% vs. 53\% $\mathrm{P}=0.8$ ) (26) and the results between the two techniques are similar for the median survival (16.2 vs. 19.2 months $\mathrm{P}=0.92)$ (30). A propensity-matched analysis on the long-term outcomes between EPP and EP/D (31) showed a better overall survival in favor of lung-sparing surgery with a statistically significant difference $(32 \mathrm{vs}$. 

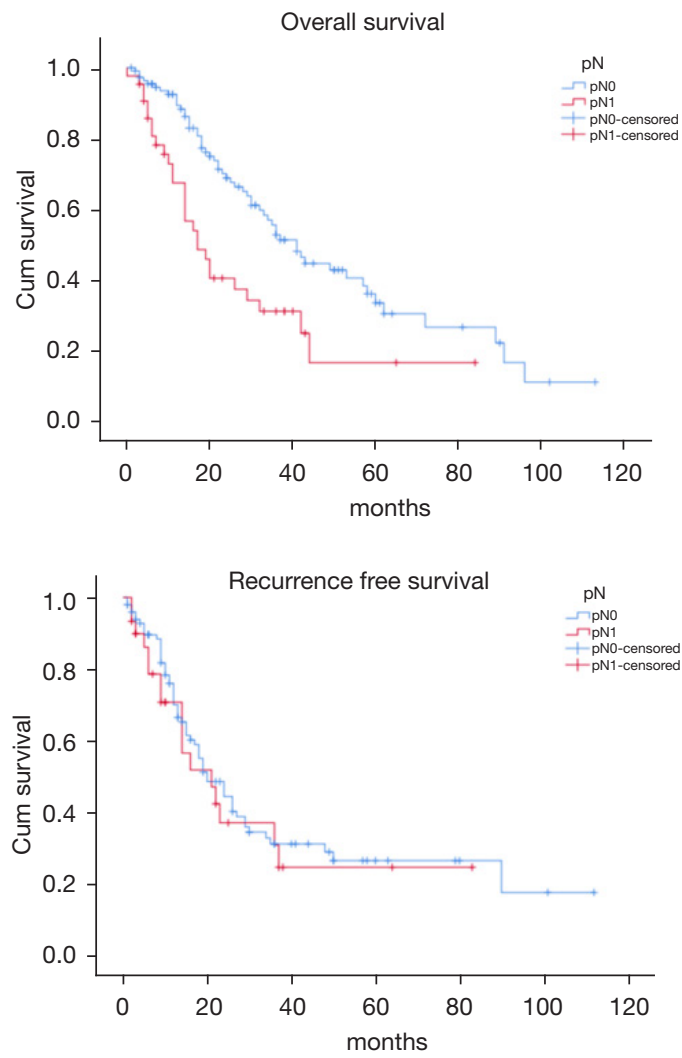

Figure $4 \mathrm{pN}$-factor. Analysis of prognostic factors. pN-status for OS $(\mathrm{P}=0.001)$ and for RFS $(\mathrm{P}=0.57)$. OS, overall survival; RFS, recurrence-free survival.

23 months $\mathrm{P}=0.031$ ), How this may correlate with $\mathrm{OS}$ is still unclear, but it has been suggested that a more conservative approach would provide a better state of health to deal with the possible relapse, mostly in a context of multimodal treatment. In a recent report (9), the joint NCI-IASLCMARF task force, published a proposal to standardize the surgical treatment. It is assumed that the MCR can be achieved by $\mathrm{P} / \mathrm{D}$, saving pericardium and diaphragm. The authors stated that every attempt should be made to preserve as much normal anatomy as possible, to maximize the benefit of the tumour cytoreduction. As reported by Sugarbaker (22), the reliability of lung-sparing surgery in achieving the MCR has always been a matter of debate, regarding the risk of recurrence due to the minor control of the margins of resection (32). This was attributable to the variability of the nomenclature for lung-sparing procedures and to the different attitudes of the operators $(17,33,34)$. Some surgeons are more inclined to resect systematically diaphragm and pericardium, conversely,
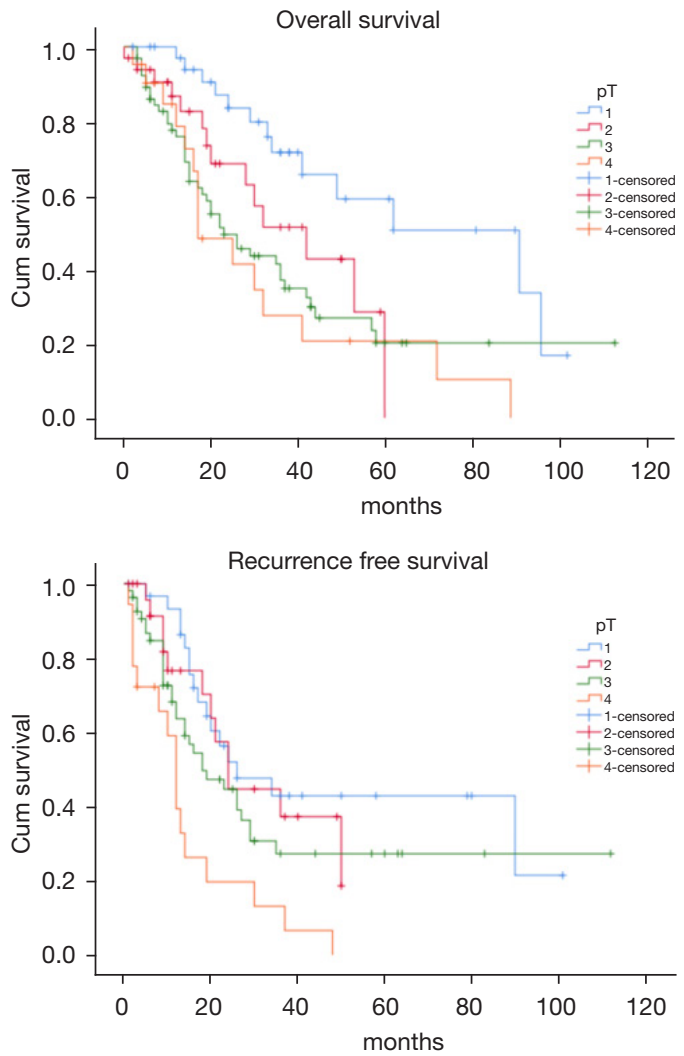

Figure 5 pT-factor. Analysis of prognostic factors. pT-status for OS $(\mathrm{P}=0.002)$ and for RFS $(\mathrm{P}=0.001)$. OS, overall survival; RFS, recurrence-free survival.

other surgeons plan the standard P/D only for patients at lower stage. In our analysis the decision to preserve the anatomy is taken by surgeons during pleurectomy and is driven by repeated intraoperative frozen sections on the areas where the presence of disease is deemed suspicious. As reported, a significant improvement of survival $(\mathrm{P}=0.007)$ was observed when lung-sparing surgery was performed without pericardial and/or diaphragmatic resection/reconstruction (Figure 2). The impact on survival of the conservation of the normal anatomy has not been clearly defined, but it is reasonable to retain the maximum possible functionality to increase the tolerance to further treatments in case of possible relapse. The data from our patients were reviewed according with the eighth edition of TNM staging proposed by IASLC which has brought important changes in the staging of MPM (17-19). The authors assigned the $\mathrm{N} 1$ descriptor for the involvement of the ipsilateral lymph-nodes, collapsing the previous $\mathrm{N} 1$ and N2 categories (18) of the seventh edition. In the 
Table 4 Multivariate analysis for OS and RFS

\begin{tabular}{|c|c|c|c|c|c|c|}
\hline Factors & \multicolumn{3}{|c|}{ os } & \multicolumn{3}{|c|}{ RFS } \\
\hline$P / D$ vs. EP/D & 1.746 & $1.105-2.758$ & 0.017 & 1.317 & $0.830-2.091$ & 0.24 \\
\hline pN0 vs. pN1 & 2.038 & $1.281-3.241$ & 0.003 & 1.051 & $0.608-1.817$ & 0.85 \\
\hline R2 surgery & 1.739 & $0.989-3.057$ & 0.055 & 2.593 & $1.474-4.558$ & 0.001 \\
\hline
\end{tabular}

OS, overall survival; RFS, recurrence free survival; P/D, pleurectomy/decortication; EP/D, extended pleurectomy/decortication.

eighth edition N2 categories is used to define contralateral nodes involvement. For the revision of the T-component, they defined the staging through multiple descriptors. In $\mathrm{T} 2$ and $\mathrm{T} 3$ stages, the invasion of the diaphragm and/or the pericardium is just one of the features of the disease, moreover it might be absent if those stages are assigned for the chest wall or mediastinal fat involvement, as most frequently observed (17). For that, the respect of the normal anatomy, when possible, should be taken into account in the surgical plan, especially since it has been proposed as a goal in the project for a standardized approach (9). In our series the pathological TNM-stage, $\mathrm{pT}$ and $\mathrm{pN}$ status were found to be significantly related to better survival (Figures 3-5). In accordance with these data, in our cohort the median survival time of 91 months (SE 26.679; $95 \%$ CI: 38.71-143.29) was recorded for Stage IA which refers to a disease limited to the pleura without involvement of other structures. In the multivariate analysis (Table 4), these findings were confirmed, defining $\mathrm{P} / \mathrm{D}$ and $\mathrm{pN} 0$ as independent prognostic factors for the improved survival outcome ( $\mathrm{P}=0.017$ and $\mathrm{P}=0.003$ respectively). A research on post-recurrence survival after P/D (21) showed that local relapse is the most frequent pattern of initial recurrence after surgery, which confirms the results published by Baldini et al. (35) on MPM treated with extrapleural pneumonectomy (EPP). They reported a recurrence rate of $63.3 \%$ with a median RFS of 19 months and described the recurrence-free interval and the post-recurrence treatment as prognostic factors for favorable outcomes. A meta-analysis published by Kostron et al. compared also the recurrence free survival between lung-sparing surgery and EPP, showing that the relapse in MPM did not depend on the extension of the surgery (15 vs. 13 months with $\mathrm{P}=0.2)$ (31). In our analysis a significant association $(\mathrm{P}<0.001)$ between OS and RFS was also observed. The 74 patients $(57.36 \%)$ who relapsed after more than 12 months from surgery, showed a survival rate of $61.2 \%$ at 2 years and of $36.7 \%$ at 5 years. Even if the strong tendency to relapse was evident (83.2\%), the mechanisms of recurrence are still not completely explained and the impact of different variables on RFS must be cautiously interpreted. Analysis of the RFS, with univariate analysis (Table 3), showed that the relevance of $\mathrm{pT}$ and $\mathrm{pN}$ factors seems to be divergent: lymph node involvement showed a lower significance as a predictor for the risk of relapse $(\mathrm{P}=0.57)$, whereas $\mathrm{pT}$ status resulted in a stronger association with disease-free survival ( $\mathrm{P}=0.001)$. Therefore, after $\mathrm{P} /$ $\mathrm{D}$ a longer median disease-free interval was recorded (26 months) when compared to EP/D (15 months), even if it did not show a significant impact on RFS $(\mathrm{P}=0.1)$. In the multivariate analysis (Table 4) the only variable related to a significant independent association with the occurrence of relapse was the R2 surgery.

\section{Study limitations}

This study was designed as a retrospective analysis conducted over 10 years in a single high-volume center for the treatment of MPM. This might be a source of bias for the changes that occurred over the years in treatment strategy, in TNM grouping and in guidelines recommendations. A possible risk of bias might derive from the pathological staging which is defined by the surgeons during pleurectomy.

\section{Conclusions}

A cohort of patients with epithelial MPM undergoing lungsparing surgery was analyzed. Benefits for survival were observed when diaphragm and pericardium were preserved. TNM variables were evaluated according with the eighth edition of the TNM staging system. Whether the $\mathrm{N}$ factor is determinant for OS, it appeared to be less involved in the development of initial relapse. The recurrence-free survival seemed to be not affected by the type of surgery. These data need to be sustained by further studies, to confirm if the 
systematic substitution of the diaphragm and pericardium might be avoided, in case of absence of tumor infiltration.

\section{Acknowledgments}

Funding: All authors are grateful to $\operatorname{Redax}^{\circledR}$ S.p.A. for funding the article processing charges.

\section{Footnote}

Reporting Checklist: The authors have completed the STROBE reporting checklist. Available at https://dx.doi. org/10.21037/jtd-21-691

Data Sharing Statement: Available at https://dx.doi. org/10.21037/jtd-21-691

Peer Review File: Available at https://dx.doi.org/10.21037/ jtd-21-691

Conflicts of Interest: All authors have completed the ICMJE uniform disclosure form (available at https://dx.doi. org/10.21037/jtd-21-691). All authors report funding from Redax S.p.A. for the article processing charges.

Ethical Statement: The authors are accountable for all aspects of the work in ensuring that questions related to the accuracy or integrity of any part of the work are appropriately investigated and resolved. The study was conducted in accordance with the The Declaration of Helsinki (as revised in 2013). The study was approved institutional ethics committee of AULSS3 Serenissima of Venice-Italy (Prot. 0003576 of 11/01/2021) and individual consent for this retrospective analysis was waived.

Open Access Statement: This is an Open Access article distributed in accordance with the Creative Commons Attribution-NonCommercial-NoDerivs 4.0 International License (CC BY-NC-ND 4.0), which permits the noncommercial replication and distribution of the article with the strict proviso that no changes or edits are made and the original work is properly cited (including links to both the formal publication through the relevant DOI and the license). See: https://creativecommons.org/licenses/by-nc-nd/4.0/.

\section{References}

1. Merritt N, Blewett CJ, Miller JD, et al. Survival after conservative (palliative) management of pleural malignant mesothelioma. J Surg Oncol 2001;78:171-4.

2. Kindler HL, Ismaila N, Armato SG 3rd, et al. Treatment of Malignant Pleural Mesothelioma: American Society of Clinical Oncology Clinical Practice Guideline. J Clin Oncol 2018;36:1343-73.

3. Scherpereel A, Astoul P, Bass P, et al. Guidelines of the European Respiratory Society and the European Society of Thoracic Surgeons for the management of malignant pleural mesothelioma. Eur Respir J 2010;35:479-95.

4. Baas P, Fennell D, Kerr KM, et al. Malignant pleural mesothelioma: ESMO Clinical Practice Guidelines for diagnosis, treatment and follow-up. Ann Oncol 2015;26 Suppl 5:v31-9.

5. Cao C, Tian D, Manganas C, et al. Systematic review of trimodality therapy for patients with malignant pleural mesothelioma. Ann Cardiothorac Surg 2012;1:428-37.

6. Hiddinga BI, van Meerbeeck JP. Surgery in mesothelioma--where do we go after MARS? J Thorac Oncol 2013;8:525-9.

7. Abdel-Rahman O, Elsayed Z, Mohamed H, et al. Radical multimodality therapy for malignant pleural mesothelioma. Cochrane Database Syst Rev 2018;1:CD012605.

8. Larose F, Quigley N, Lacasse Y, et al. Malignant pleural mesothelioma: Comparison of surgery-based trimodality therapy to medical therapy at two tertiary academic institutions. Lung Cancer 2021;156:151-6.

9. Friedberg JS, Culligan MJ, Tsao AS, et al. A Proposed System Toward Standardizing Surgical-Based Treatments for Malignant Pleural Mesothelioma, From the Joint National Cancer Institute-International Association for the Study of Lung Cancer-Mesothelioma Applied Research Foundation Taskforce. J Thorac Oncol 2019;14:1343-53.

10. Flores RM. Pleurectomy decortication for mesothelioma: The procedure of choice when possible. J Thorac Cardiovasc Surg 2016;151:310-2.

11. Friedberg JS, Simone CB 2nd, Culligan MJ, et al. Extended Pleurectomy-Decortication-Based Treatment for Advanced Stage Epithelial Mesothelioma Yielding a Median Survival of Nearly Three Years. Ann Thorac Surg 2017;103:912-9.

12. Bovolato $\mathrm{P}$, Casadio $\mathrm{C}$, Billè $\mathrm{A}$, et al. Does surgery improve survival of patients with malignant pleural mesothelioma?: a multicenter retrospective analysis of 1365 consecutive patients. J Thorac Oncol 2014;9:390-6.

13. Lang-Lazdunski L, Bille A, Lal R, et al. Pleurectomy/ decortication is superior to extrapleural pneumonectomy in 
the multimodality management of patients with malignant pleural mesothelioma. J Thorac Oncol 2012;7:737-43.

14. Treasure T, Lang-Lazdunski L, Waller D, et al. Extrapleural pneumonectomy versus no extra-pleural pneumonectomy for patients with malignant pleural mesothelioma: clinical outcomes of the Mesothelioma and Radical Surgery (MARS) randomised feasibility study. Lancet Oncol 2011;12:763-72.

15. Novello S, Pinto C, Torri V, et al. The Third Italian Consensus Conference for Malignant Pleural Mesothelioma: State of the art and recommendations. Crit Rev Oncol Hematol 2016;104:9-20.

16. Byrne MJ, Nowak AK. Modified RECIST criteria for assessment of response in malignant pleural mesothelioma. Ann Oncol 2004;15:257-60.

17. Rice D, Rusch V, Pass H, et al. Recommendations for uniform definitions of surgical techniques for malignant pleural mesothelioma: a consensus report of the international association for the study of lung cancer international staging committee and the international mesothelioma interest group. J Thorac Oncol 2011;6:1304-12.

18. Nowak AK, Chansky K, Rice DC, et al. The IASLC Mesothelioma Staging Project: Proposals for Revisions of the T Descriptors in the Forthcoming Eighth Edition of the TNM Classification for Pleural Mesothelioma. J Thorac Oncol 2016;11:2089-99.

19. Rice D, Chansky K, Nowak A, et al. The IASLC Mesothelioma Staging Project: Proposals for Revisions of the N Descriptors in the Forthcoming Eighth Edition of the TNM Classification for Pleural Mesothelioma. J Thorac Oncol 2016;11:2100-11.

20. Rusch VW, Chansky K, Kindler HL, et al. The IASLC Mesothelioma Staging Project: Proposals for the M Descriptors and for Revision of the TNM Stage Groupings in the Forthcoming (Eighth) Edition of the TNM Classification for Mesothelioma. J Thorac Oncol 2016;11:2112-9.

21. Nakamura A, Takuwa T, Hashimoto M, et al. Clinical Outcomes With Recurrence After Pleurectomy/ Decortication for Malignant Pleural Mesothelioma. Ann Thorac Surg 2020;109:1537-43.

22. Sugarbaker DJ. Macroscopic complete resection: the goal of primary surgery in multimodality therapy for pleural mesothelioma. J Thorac Oncol 2006;1:175-6.

23. van Gerwen M, Wolf A, Liu B, et al. Short-term outcomes of pleurectomy decortication and extrapleural pneumonectomy in mesothelioma. J Surg Oncol 2018;118:1178-87.

24. Wolf AS, Flores RM. Current Treatment of Mesothelioma: Extrapleural Pneumonectomy Versus Pleurectomy/Decortication. Thorac Surg Clin 2016;26:359-75.

25. Cao C, Tian DH, Pataky KA, et al. Systematic review of pleurectomy in the treatment of malignant pleural mesothelioma. Lung Cancer 2013;81:319-27.

26. Taioli E, Wolf AS, Flores RM. Meta-analysis of survival after pleurectomy decortication versus extrapleural pneumonectomy in mesothelioma. Ann Thorac Surg 2015;99:472-80.

27. Burt BM, Cameron RB, Mollberg NM, et al. Malignant pleural mesothelioma and the Society of Thoracic Surgeons Database: an analysis of surgical morbidity and mortality. J Thorac Cardiovasc Surg 2014;148:30-5.

28. Verma V, Ahern CA, Berlind CG, et al. National Cancer Database Report on Pneumonectomy Versus LungSparing Surgery for Malignant Pleural Mesothelioma. J Thorac Oncol 2017;12:1704-14.

29. Taioli E, Wolf AS, Camacho-Rivera M, et al. Determinants of Survival in Malignant Pleural Mesothelioma: A Surveillance, Epidemiology, and End Results (SEER) Study of 14,228 Patients. PLoS One 2015;10:e0145039.

30. Nakas A, Waller D. Predictors of long-term survival following radical surgery for malignant pleural mesothelioma. Eur J Cardiothorac Surg 2014;46:380-5; discussion 385 .

31. Kostron A, Friess M, Inci I, et al. Propensity matched comparison of extrapleural pneumonectomy and pleurectomy/decortication for mesothelioma patients. Interact Cardiovasc Thorac Surg 2017;24:740-6.

32. Hasegawa S. Extrapleural pneumonectomy or pleurectomy/decortication for malignant pleural mesothelioma. Gen Thorac Cardiovasc Surg 2014;62:516-21.

33. Marulli G, Breda C, Fontana P, et al. Pleurectomydecortication in malignant pleural mesothelioma: are different surgical techniques associated with different outcomes? Results from a multicentre study. Eur J Cardiothorac Surg 2017;52:63-9.

34. Waller DA, Bilancia R, Bille A, et al. Standardizing 
Surgical Treatment of Malignant Pleural Mesothelioma. J Thorac Oncol 2020;15:e73-4.

35. Baldini EH, Richards WG, Gill RR, et al. Updated

Cite this article as: Breda C, Furia S, Lucchini G, Zaccaria A, Verderi E, Natale G, Lo Giudice F, Cavallin R, Ferronato A, Fontana P. Long-term outcomes after lungsparing surgery for epithelial mesothelioma. J Thorac Dis 2021;13(11):6283-6293. doi: 10.21037/jtd-21-691 patterns of failure after multimodality therapy for malignant pleural mesothelioma. J Thorac Cardiovasc Surg 2015;149:1374-81. 